
cultural y científica entre Perú y Francia

\title{
Las revoluciones francesas en el Perú: una reinterpretación (1789-1848)
}

Las révolutions françaises au Pérou : une réinterprétation (1789-1848)

The French Revolutions in Peru: a reinterpretation (1789-1848)

\section{Claudia Rosas Lauro y José Ragas Rojas}

\section{OpenEdition}

Journals

Edición electrónica

URL: http://journals.openedition.org/bifea/4460

DOI: $10.4000 /$ bifea.4460

ISSN: 2076-5827

Editor

Institut Français d'Études Andines

Edición impresa

Fecha de publicación: 8 mayo 2007

Paginación: 51-65

ISSN: 0303-7495

Referencia electrónica

Claudia Rosas Lauro y José Ragas Rojas, «Las revoluciones francesas en el Perú: una

reinterpretación (1789-1848) », Bulletin de l'Institut français d'études andines [En línea], 36 (1) | 2007,

Publicado el 08 mayo 2007, consultado el 10 diciembre 2020. URL : http://journals.openedition.org/ bifea/4460 ; DOI : https://doi.org/10.4000/bifea.4460

Les contenus du Bulletin de l'Institut français d'études andines sont mis à disposition selon les termes de la licence Creative Commons Attribution - Pas d'Utilisation Commerciale - Pas de Modification 4.0 International. 


\title{
Las revoluciones francesas en el Perú: una reinterpretación (1789-1848)
}

\author{
Claudia Rosas Lauro* \\ José Ragas Rojas**
}

\begin{abstract}
Resumen
Los movimientos revolucionarios, su origen, influencia y alcance, han sido temas recurrentes en la historiografía peruana. En el caso específico de las revoluciones francesas (la de 1789 sobre todo), existe una serie de imágenes que oscilan entre el sobredimensionamiento de su impacto (al calificarla de suceso clave en la independencia peruana) y un escaso conocimiento de coyunturas posteriores, como la de 1848. El presente artículo tiene como finalidad ofrecer nuevos enfoques sobre el impacto de las revoluciones francesas en el Perú, en especial de las coyunturas revolucionarias de 1789 y 1848 . Para ello, estudia los mecanismos de difusión y circulación de la información, en particular el rol del periodismo, los espacios de sociabilidad y la opinión pública; asimismo, aborda la construcción de la imagen ambigua de las revoluciones y la política del Estado y las autoridades frente a ellas. Además, el artículo ofrece una aproximación a algunas de las transformaciones provocadas en la cultura política del periodo estudiado.
\end{abstract}

Palabras clave: Revolución Francesa, opinión pública, cultura política, Perú, siglos XVIII-XIX

\section{Las révolutions françaises au Pérou: une réinterprétation (1789-1848)}

\section{Résumé}

Les mouvements révolutionnaires, leurs origines, influences et ampleurs ont été depuis longtemps dans l'agenda de l'historiographie péruvienne. Par rapport au cas spécifique des révolutions françaises (surtout celle de 1789), il existe une série d'images qui alternent entre la survalorisation de leur impact (consisérée comme événement clé dans l'indépendance péruvienne) et le manque de prise en compte des conjonctures ultérieures telles que la révolution de 1848. Cet article propose de nouvelles approches sur l'impact des révolutions françaises, notamment les conjonctures révolutionnaires de 1789

* Universidad de Florencia, Pontificia Universidad Católica del Perú (PUCP). E-mail: crosas@pucp.edu.pe

** Pontificia Universidad Católica del Perú (PUCP). E-mail: jragas@pucp.edu.pe 
et 1848. Dans ce sens, l'article analyse les mécanismes de diffusion et de circulation de l'information, en particulier le rôle de la presse, ainsi que les espaces de sociabilité et l'opinion publique. En même temps, ce travail examine la construction des images ambivalentes que ces événements ont déclenchés, ainsi que la politique d'Etat et la position des autorités vis-à-vis de ceux-ci. Cette démarche permet d'aborder quelques transformations au sein de la culture politique dans la période choisie.

Mots clés : Révolution Française, opinion publique, culture politique, Pérou, siècles XVIII-XIX

\title{
The French Revolutions in Peru: a reinterpretation (1789-1848)
}

\begin{abstract}
Revolutionary movements, as well as their origin, influence and consequences have been recurring topics in Peruvian historiography. Several images exist regarding the specific case of the French Revolutions (1789, mostly). There fluctuate between overemphasizing their impact (being represented as a key event in Peruvian independence) and scarce knowledge of ensuing events, such as 1848. This article aims to offer new perspectives on the impact of the French Revolutions in Peru, focusing on the revolutionary contexts of 1789 and 1848. In order to do so, the article focuses on the mechanisms of dissemination and circulation of information, particularly the role of journalism, public opinion and spaces for socialization. It also deals with the construction of the ambiguous imagery of the revolutions and the policies related to them emanating from the State and its officials. In addition, the article examines some of the transformations that took place in the political culture of the studied period.
\end{abstract}

Key words: French Revolution, public opinion, political culture, Peru, XVIIIth-XIXth century

\section{INTRODUCCIÓN 1}

Lima, 14 de julio de 1889. Los Hermanos Mayores han decidido reunirse para celebrar, a su manera, el primer centenario de la Revolución Francesa. Se trata de una reunión sencilla, pero de profundo valor simbólico pues la fecha en cuestión conmemora también, como lo hace notar el Gran Maestre en su discurso, los «100 combates titánicos», representados en «la tríada hermosa de nuestros dogmas fundamentales; donde el azul, símbolo de la esperanza es la libertad; el rojo figura la sangre pronta a derramarse por la libertad de los hermanos; el blanco, cándido, puro, con la negación de matices, proclama la libertad». La ceremonia llega a su clímax cuando uno de los presentes ejecutó en el piano el «Himno de las Naciones» (Moreno Alonso, 1993).

Si alguno de los Hermanos Mayores, o incluso el propio Gran Maestre, hubiese salido a la calle, se habría encontrado con un ambiente menos ceremonial y más festivo, de limeños que celebraban sin percatarse demasiado de la existencia de los masones locales. Y es que la celebración por

1 Este artículo se basa en la ponencia presentada en el Coloquio «La Presencia Francesa en el Perú», organizado por el Instituto Francés de Estudios Andinos y el Congreso de la República del Perú del 4 al 8 de julio del 2005. Sobre la base de este trabajo se escribió un ensayo que ganó el Premio Literario «20 ans du CECUPE» del Centro Cultural Peruano en París el 29 de junio del 2006. El ensayo será publicado próximamente en versión bilingüe en París en la editorial Mare et Martin, bajo el título Marianne en los Andes. El impacto de las Revoluciones Francesas en el Perú, 1789-1968. Queremos dejar constancia de nuestro agradecimiento a Víctor Peralta, Charles Walker y Pablo Ortemberg por sus comentarios a una versión previa de este artículo. También queremos agradecer a Jorge Bayona por la traducción de la sumilla al inglés. 
los cien años de la Revolución se llevó a cabo a lo largo del día; por la mañana, se organizó una pequeña reunión en el local de la compañía de bomberos «France», para luego proseguir en el Palacio de la Exposición donde, si seguimos a la prensa, se habrían congregado cerca de 15000 personas para presenciar el espectáculo de juegos, globos aerostáticos y discursos que ahí se desarrollaban. Como no podía ser de otra manera, los símbolos de Francia estuvieron omnipresentes: la Marsellesa fue ejecutada magistralmente, la Torre Eiffel —ícono por excelencia del industrialismo- estuvo representada por un castillo, y las fachadas de los miembros de la colonia ondeaban la tricolor. Como una muestra de deferencia —o de subyugación, o ambas- el cónsul y el alcalde de Lima pronunciaron sus discursos en la lengua de la nación homenajeada.

Esta celebración hizo que los limeños olvidaran las tristezas de la guerra que había terminado solo cinco años antes. Por ello no llama la atención que el recuerdo de la derrota termine orientando las ceremonias de este primer centenario. ¿Qué mejor manera de festejar el legado de la revolución si no es rememorando la «fraternidad» de la colonia hacia los peruanos que se encontraban luchando? Porque, según lo hacen saber a los presentes, las tareas de los franceses radicados en la capital no fueron menores: matar chilenos, auxiliar a los heridos y presionar al invasor para que detenga la ejecución de sospechosos peruanos².

No todos han recibido a la Revolución con el mismo entusiasmo. Estos últimos doscientos años transcurridos desde la toma de la Bastilla y los más de ciento cincuenta desde las revueltas de los quarante-huitards, vieron oscilar la interpretación sobre ambos fenómenos conforme el vaivén político y los historiadores afinaban o descubrían elementos que no habían sido considerados hasta entonces. El bicentenario parecía ofrecer un momento adecuado para realizar un balance ( ¿o un ajuste de cuentas?) entre las diversas interpretaciones sobre el 89: desde las «jacobinas» o socialistas, difundidas al calor de la Revolución Rusa3, hasta las «girondinas» o de derecha, que veían en el 89 un peligroso legado que era necesario neutralizar (Furet, 1999). En el medio se presentaba una historia cultural que había optado por acercarse a temas como la opinión pública, los emblemas que se habían establecido, los cambios en las costumbres, las transformaciones en la lectura y la circulación de libros ${ }^{4}$, etc.

El presente texto busca ofrecer nuevos enfoques sobre el impacto de las revoluciones francesas en el Perú, en especial la de 1789 y la de 1848. No podemos dejar de mencionar las coyunturas de 1808 con la invasión napoleónica de la península ibérica, y las de 1820 y 1830 que si bien no tuvieron una gran influencia en relación a las anteriores, ameritan estudios más detallados. Precisamente, esta reflexión se apoya en estudios de largo aliento previamente hechos sobre ambas coyunturas revolucionarias ${ }^{5}$. Hemos dividido el trabajo en tres partes: la primera, trata de los mecanismos de difusión y circulación de la información, en particular el rol del periodismo, los espacios de sociabilidad y la opinión pública; el segundo punto, aborda la construcción de la imagen de la revolución, caracterizada por su ambigüedad, en cada una de las coyunturas sujetas a análisis, así como la política del Estado y las autoridades frente al hecho revolucionario; y, finalmente, el tercer acápite, ofrece una aproximación a algunas de las transformaciones provocadas en la cultura política del periodo estudiado.

2 «Crónica. Colonia francesa» y «Las fiestas de ayer». El Comercio (Lima, 15 de julio de 1889).

3 No son pocos los que establecieron la ligazón entre el 89 francés y el octubre rojo bolchevique. Deutscher (1970) y Carr (1985).

4 Cualquier inventario resultaría incompleto, pero mencionemos los textos más conocidos de esta corriente: Agulhon (1979); Darnton (1987); Chartier (1995). Para una visión global de este periodo, ver Roche (1998). Tampoco faltaron propuestas como la de Simon Schama (1990) que prefería narrar la Revolución en clave de crónica, como lo habrían hecho los contemporáneos.

5 Este texto se basa en dos investigaciones realizadas anteriormente para las coyunturas de 1789 y 1848 . Véase respectivamente, Rosas Lauro (2006) y Ragas (2003a); cuya versión ampliada y revisada será editada bajo el título de Ciudadanos de lo imposible. Opinión pública, partidos políticos y corrupción en el Perú (1808-1854). 


\section{PERIODISMO, ESPACIOS DE SOCIABILIDAD Y FORMACIÓN DE LA OPINIÓN PÚBLICA}

Un aspecto saltante que nos muestra el impacto de las coyunturas revolucionarias es el dinamismo y la evolución de los mecanismos de circulación y difusión de la información que, evidentemente, van increcendo del 89 al 486. En este escenario el periodismo va tomando un rol fundamental, y midiendo el número de los periódicos editados, su tiraje y difusión, los personajes que estaban detrás de la empresa editorial, el tipo de censura al que fueron sujetos, el tipo de información que ofrecían al público lector; podemos aproximarnos a un aspecto vital y dinámico de la práctica política y sus transformaciones en este periodo. A fines del siglo XVIII apareció la prensa moderna y vieron la luz cuatro periódicos, dos de los cuales contenían noticias sobre la Revolución Francesa; es más, uno de ellos, la Gaceta de Lima de 1793, estaba dedicado íntegramente a informar sobre el hecho revolucionario, lo que lo convierte en el primer periódico de carácter internacional ${ }^{7}$. Se trataba de un periódico oficial que empezó a publicarse a partir del aguillotinamiento de Luis XVI y la declaración de guerra a Francia. Al lado del estilo cronístico e informativo de la Gaceta, estaba el Mercurio Peruano, publicado por la Sociedad de Amantes del País entre 1790 y 1795, que presentaba otro tipo de textos como los literarios o documentos oficiales ${ }^{8}$. Editados en Lima, se difundieron también a provincias, donde recién se publicarán periódicos en 1821 cuando las tropas realistas se lleven la imprenta a Cuzco9.

Hacia la década de 1840 una serie de factores permitirán la instalación de imprentas y de editores dispuestos a publicar periódicos en el interior del país. Entre estos factores se encontraba la existencia de «periodistas», la expectativa por parte de un público cada vez en aumento, la facilidad con que el papel llegaba a los puertos limeños, un mayor número de espacios públicos donde comentar las noticias y vender los periódicos y, sobre todo, una permisividad mayor por parte de las autoridades, que no podían censurar las informaciones a la manera de las autoridades metropolitanas porque hubieran ido en contra de los principios liberales que resguardaban (Ragas, 2003b).

Gran parte de la información contenida en los periódicos provenía de Europa. Para el 89 las noticias pasaban por la censura del gobierno metropolitano o eran filtradas desde las gacetas madrileñas; mientras que para el 48 el filtro actuaba de forma muy limitada. Este aspecto es interesante, pues las revoluciones desataron una suerte de globalización de la información a escala mundial, donde las noticias llegaban distorsionadas por la censura y el tiempo, o eran reelaboradas muchas veces a nivel local, multiplicando al infinito las interpretaciones sobre un mismo acontecimiento. Sin embargo, con el tiempo surgen cada vez más escritos locales en donde los actores se pronuncian sobre los acontecimientos europeos, lo cual llega al ápice durante el 48. Desde la Independencia la propaganda y contrapropaganda marcaron con fuerza el periodismo, al punto que éste se convirtió en la arena por excelencia de los debates públicos y políticos — véase Macera (1977a) y Martínez Riaza (1985)—. No solo eso, sino que además se convirtió en el pilar más importante de legitimidad dentro de la sociedad, en un proceso que se fue conformando desde inicios del siglo XIX.

Desde 1790 la lectura de temas políticos fue adquiriendo progresivamente mayor relevancia frente a la lectura de temas de tipo religioso (Peralta, 1977)10, lo cual se evidencia en las coyunturas del 1789, 1808 y 1812, en que los acontecimientos políticos de España y Europa

6 El tema para la coyuntura de 1789 está desarrollado en Rosas Lauro (2006: 53-96), y para el 48 en Ragas (2003a).

7 Consúltese Durand (1983); Rosas Moscoso (1989) y Rosas Lauro (2006).

8 Un estudio exhaustivo de este periódico se encuentra en Clément (1997). También Hampe (1982) y Rosas Lauro (2006).

9 Para el periodismo cuzqueño, entre otros, véase Denegri Luna (1962-1963); Cahuata (1990); Walker (2000); Rosas Lauro (2000a); Glave (2004).

10 Para el caso mexicano, se puede consultar Guerra (1993). 
tienen repercusiones cada vez más sentidas en el contexto peruano11. Esta situación favoreció la lectura de los periódicos que contenían noticias de actualidad sobre el acontecer político, y podemos pensar que así continuó durante la centuria hasta el 48. Al lado de los periódicos, estaban los folletos, los pasquines y las cartas que ya en fecha temprana se difundieron con rapidez y facilidad entre los habitantes del Perú. Desde la Declaración de los Derechos del Hombre y del Ciudadano12, carta fundamental de la revolución, hasta escritos de los mismos líderes revolucionarios tales como el Discurso de Petion o de un buen francés ${ }^{13}$. Algunos circulaban en francés, otros fueron traducidos al castellano.

Los pasquines también hicieron su aparición hacia 1794 sobre todo en Lima, pero también fueron remitidos por correo a las autoridades de algunas provincias (De la Puente Candamo, 1948). Manifestaban una dura crítica al gobierno colonial y una clara alabanza al sistema francés, oponiendo tiranía española a libertad francesa. Se fijaron en lugares importantes de la ciudad para que los transeúntes los leyeran. Aunque no contamos con inventarios tan completos como los editados por José Toribio Medina a partir de las impresiones salidas de la imprenta limeña, es posible aventurar que los folletos continuaron con su importancia en contenido y número en las primeras décadas luego de la independencia, en un espiral iniciado en 1808. Los motivos de este éxito son predecibles: su distribución amplia (en ocasiones gratuita por quienes deseaban que el contenido fuese conocido por la mayor cantidad posible de personas), un precio bajo, y un formato fácil de llevar.

Como ya lo mencionamos, la difusión de libros fue más difícil y lenta en la coyuntura del 89 debido a la censura y a que la cultura libresca pertenecía a un sector muy restringido de la sociedad colonial por su elevado costo, necesidad de cierto nivel de educación para su comprensión, su dificultad de adquisición por la censura ${ }^{14}$, etc. Esto no impidió la difusión de los eventos revolucionarios, a través de libros publicados en España y que penetraron en territorio peruano, sino de traducciones y ediciones como la que hiciera Guillermo del Río (1805), quien tradujo del francés al castellano y editó dos tomos de un Compendio Histórico de la Revolución Francesa desde el año de 1789 hasta el de 1802. Si bien contaba con la licencia real, al leer las conclusiones se percibe que la censura dejó pasar un texto que a todas luces manifestaba una postura laudatoria de los sucesos franceses. En cambio, en la coyuntura de 1808 tuvo mayor fuerza la proliferación de una literatura antinapoleónica15. Un buen ejemplo de ello es Centinela contra franceses de Antonio de Capmany, escrito en Madrid y reimpreso en la Imprenta de Niños Expósitos de Lima en 1809 (Capmany, 1809). Pero esta riqueza de información sobre la circulación de libros se pierde con el fin del aparato colonial. Lo que sí sabemos es que se abrieron más librerías, sobre todo extranjeras, que permitieron el acceso a lecturas en otros idiomas. Paradójicamente, a diferencia de la coyuntura anterior, donde las lecturas políticas habían desplazado a las religiosas, uno de los libros con mayor difusión después de 1820 sería la Biblia, debido al proyecto sanmartiniano de apoyar el método lancasteriano de lectura16.

La difusión de la prensa desplazó la abundante publicación de libros de los años anteriores, con excepción de los folletos, que vieron incrementar su número por su valor como arma política. Esto dio lugar a una relación inversa entre ambos movimientos, pues si en el 89 la información periodística es controlada pero abundan los folletos, en el 48 el principal canal de información

11 Sobre el tema, ver la respuesta de Víctor Peralta (2005) a un artículo de François-Xavier Guerra (2002).

12 «La Declaración de los Derechos del Hombre y del Ciudadano». París, 1789. Biblioteca Nacional de Lima, Manuscritos, c3728.

13 «Causa seguida contra Carlos Fornier por expresiones sediciosas». Archivo General de la Nación, Real Audiencia, Leg. 78, c. 950. Año 1794. El texto fue publicado en el Mercurio Peruano.

14 El trabajo clásico de Pablo Macera (1977b) nos ilustra sobre el ambiente libresco del siglo XVIII mediante una revisión de las bibliotecas limeñas. Una visión más actual está en González (2005). Son importantes los trabajos de Guibovich (2003) y González (1999). Sin embargo, faltaría un estudio para las últimas décadas del XVIII y las primeras del XIX que son las que nos interesan.

15 Para un estudio de la literatura antinapoleónica consúltese Nieto Vélez (1960b).

16 Véase los estudios de Fonseca (2001) y Cubas (2001). 
es la prensa, pero no merece ningún escrito particular, como sí ocurrirá con relación a los sucesos de la Comuna treinta años después. La correspondencia complementa el caudal de información además de brindar un aspecto más íntimo del efecto producido por las revoluciones. Baste mencionar el intercambio de cartas entre el presidente Castilla y su ministro de Hacienda acerca de los posibles efectos en la economía por los sucesos europeos.

Esta gama de soportes escritos se articularon con los nacientes y dinámicos espacios públicos y de sociabilidad — Guerra \& Lempérière (1998); Gazmuri (1992); Mateus Ventura (2004) — configurando una opinión pública que para el 79 será embrionaria, pero que para el 48 habrá madurado un poco más por el desarrollo y ampliación de una serie de mecanismos de circulación de la información y la participación de la población en la discusión de temas políticos. Pero sin duda, los años de 1808 y 1814 en adelante significarán la madurez de los espacios públicos, como los cafés, las tertulias y las pulperías. Como se puede suponer, la dinámica de cada uno de estos espacios es distinta una del otra, por lo que es necesario, aunque sea brevemente, indicar en qué consistían.

Los cafés y las pulperías compartían muchos rasgos en común, acaso el más importante era el conformar los espacios por excelencia de esta nueva sociabilidad pública que se presenta hacia fines del siglo XVIII. Las pulperías podían remontar su existencia hacia el siglo XVII y se encontraban tanto en Lima como el interior del Virreinato (Garofalo, 2005)17; no así los cafés, cuya instalación era reciente —el primero del que se tienen noticias es de $1771-$ y es casi seguro que solo existían en Lima18. La escasa información de la que disponemos para ambos espacios no permite aventurar afirmaciones concluyentes sobre el rol que jugaron en la política nacional, pero por diversas informaciones se pueden deslizar algunas ideas. Indiquemos algunas de estas conjeturas para los cafés. Sabemos que estos no se extendieron a nivel nacional, ni en las postrimerías del Virreinato ni durante la primera mitad del siglo XIX19 y su número no parece haber llegado a un número significativo (no más de una docena en su mejor momento) si seguimos a Carlos Forment. ¿Es una cantidad baja o alta? En todo caso, ialta baja con respecto a qué? Es aquí donde la comparación con las pulperías viene en auxilio nuestro. Según se desprende de la detallada investigación del mismo Forment, la proporción pulperías/cafés es aplastante a favor de las primeras (Forment, 2003). Pero la información sobre los cafés, algo dispersa, permite incidir en una hipótesis más: la imagen que se tiene de ellos como elementos burgueses o elitistas podría estar muy lejana de la realidad. Diversas informaciones dan cuenta que estos cafés alternaban la venta de esta bebida con juegos de billar o incluso helados en los meses de verano, permitiendo la concurrencia de personas de sectores populares; pero esto no es raro, puesto que los cafés alemanes tenían las mismas características. Pero aún así, las noticias sobre la revolución circularon en los cafés o al menos las autoridades los consideraron focos peligrosos y necesarios de contar con vigilancia. Esta imagen de centro cultural se había mantenido intacta para mediados del siglo XIX cuando el chileno Victoriano Lastarria se sorprenda de los cafés limeños, indicando que «son numerosísimos [y] están llen[o]s a toda hora de toda clase de gentes, sin excluir a la más alta aristocracia» (Lastarria, 1967: 89; Leguía, 1989).

En un ámbito a medio camino entre lo privado y lo público se hallaban las asociaciones 20. Estas, siguiendo un modelo iniciado en Europa, agrupaban a personas con diversos intereses, como los aspectos económicos (las primeras en formarse en el siglo XVIII), hasta las patrióticas,

17 Un trabajo de largo alcance sobre las pulperías durante las primeras décadas republicanas lo está desarrollando Arnaldo Mera.

18 Algunos estudios son Mendiburu (1879); Holguín (1998). También hay referencias que da Joseph Rossi y Rubí. «Rasgo histórico y filosófico sobre los Cafés de Lima», Mercurio Peruano, t. I, N 12, 10 de febrero de 1791.

19 En 1771, apareció el primer café en Lima, cuando Francisco Serio, vecino de la ciudad, estableció un local en la calle del Correo Viejo, donde se servía café y bebidas, además de otros artículos. En 1776, Serio dejó las Animas para establecer un local más amplio y acogedor en la calle de Bodegones, famoso café que duró hasta aproximadamente mediados del siglo XIX.

20 También eran conocidas como sociedades o clubs. Nuevamente, el trabajo de Forment es uno de los más apropiados para este tema, especialmente en lo referido a la cuantificación y distribución geográfica de las asociaciones. 
pasando por otras más. Una de las más importantes fue la Sociedad Amantes del País, encargada de publicar Mercurio Peruano, un periódico patrocinado por el virrey, lo cual explica que a través de sus páginas se haya querido neutralizar el impacto del 8921 . No es que sus redactores fuesen activos promonárquicos, pero la tutela de las autoridades para la difusión del periódico implicaba hacer algunas concesiones y convertir al Mercurio en poco más que una suerte de vocero oficial.

En los siguientes años, las asociaciones se encargarán, indirectamente, de propiciar y difundir el ideal de libre vinculación en tanto todos son ciudadanos libres. Su número se multiplicó exponencialmente, tanto como las funciones de las mismas, hasta reemplazar aspectos que un débil Estado post-independencia no podía cubrir. Ya sin el control del Estado, y dentro de la efervescencia de principios liberales, el 48 vió aparecer la Sociedad Patriótica de Fraternidad, Igualdad y Unión (antecedente directo de las sociedades de veteranos de guerra), conformada por militares que esperaban en vano el cumplimiento de sus pensiones y que vieron en una asociación una forma de enfrentar la pobreza y la vejez22. El nombre ya permite adivinar un cierto parentesco ideológico con los eventos parisinos, pero otros elementos pueden brindarnos un mejor acercamiento. Todos ellos insistían en llamarse a sí mismos «ciudadanos» o «hermanos», amparados en el principio de «fraternizar para amarse, usar de igualdad para tener armonía» 23 . Tratándose de militares, el uso de un lenguaje común pudo haber implicado pasar por encima de las jerarquías castrenses (además, claro de las sociales y políticas) para establecer un proyecto común y de proyección internacional, como lo demuestra el emblema que adoptan y donde aparecen los pabellones de las naciones latinoamericanas.

Las festividades públicas, los banquetes y las ceremonias cívicas, especialmente en el 48, fueron también una ocasión propicia para difundir la Revolución a través de proclamas, arengas, discursos y símbolos. Los rituales los llevaba a cabo la monarquía para mantener la lealtad de sus súbditos. Esto era importante sobre todo por la extensión de las posesiones, más aún en el caso español, donde el virrey debía hacer las veces del soberano y transmitir la sensación de autoridad y poder a una población ágrafa (Cañeque, 2004). Complementariamente, las imágenes revolucionarias presentes en la iconografía de las monedas (Dargent, 1989), símbolos patrios, pinturas (Mujica, 2003) y demás soportes fueron otro mecanismo de difusión. Para el 89 no hemos hallado indicios en territorio peruano, si bien sabemos que para otros contextos americanos estas han podido ser rastreadas 24 .

El control de la información será más fuerte en la coyuntura del 89 debido a la presencia del gobierno colonial, que muy rápidamente entendió el peligro de la difusión de las ideas de libertad e independencia, y de la Inquisición, que si bien estaba venido a menos su poder, reactivó su actividad con ocasión del peligro sentido como inminente. Este despliegue no solo se dió en el ámbito de la vigilancia de los escritos, sino también de los lugares públicos donde se leían los textos en voz alta, se desarrollaban las conversaciones y se generaban los rumores, y participaban personas de distinta procedencia social. Sin embargo, la vigilancia y posterior represión en la década de 1790 se orientó sobre todo a los franceses residentes en el Virreinato, hecho que se repitió nuevamente en la coyuntura de 1808 con la invasión napoleónica de la península.

Un aspecto menos trabajado es aquel relacionado con la política de las autoridades frente a los súbditos franceses que se encontraban en el país cuando estas revoluciones se produjeron. Entre esas dos fechas la política exterior viró de un lado al otro. En el 89 muchos franceses residentes en el país fueron perseguidos bajo la orden de ser embarcados lo antes posibles a Europa, pues en cada francés se veía un posible conspirador. El caso de Fornier —uno de los deportados de los

\footnotetext{
21 Véase Rosas Lauro (1997, cap. 4.1); Clément (1990) y Alegre (1997).

22 Para mayor información sobre esta institución, cf. Ragas (2003a, cap. 5.5).

23 El Comercio (Lima, 2986, 16 de junio de 1848).

24 Hace falta una investigación en esta dirección como la que está llevando a cabo Pablo Ortemberg (2004) referida a las celebraciones patrias para confirmar los posibles préstamos.
} 
que se tiene mayor información — es significativo. Para la década de 1840, la colonia francesa se encontraba ocupando una notable posición en la sociedad. Mientras que en 1794 se deportó a un par de franceses, en la coyuntura de 1808 el número se incrementó a trece individuos de esta nación. Así, en tiempos del virrey Abascal se detuvo a trece franceses domiciliados en el Virreinato, que en junio de 1810 fueron embarcados hacia Cádiz (Nieto Vélez, 1960a: 77-78). Los eventos del 48 no provocaron ninguna expulsión, sino todo lo contrario. Desde París, el rey Luis Felipe ordenó a los cancilleres de los países latinoamericanos que levantasen un minucioso registro de la demanda del mercado laboral en las capitales así como las posibilidades que tendrían los franceses de poder establecerse en dichas ciudades. El propósito era evidente: el gobierno francés deseaba expulsar a las «clases peligrosas» para evitar futuras revueltas. Los cancilleres realizaron su trabajo con bastante cuidado, seleccionando los posibles oficios que podrían realizar sus compatriotas, pero no pasó de ser solo un proyecto (Pérez-Mallaína, 1980).

Como se puede apreciar del panorama trazado sobre el aspecto concerniente a la información, podemos ver de qué manera la difusión del 48 fue mayor a la del 89. De este modo, la coyuntura del 48 resultó más favorecida que la del 89 en cuanto a circulación de noticias, mayor número de imprentas, un público más ansioso de conocer noticias debido a que los periódicos incorporaban ahora más servicios, precios más accesibles, limitación de la censura del gobierno (pues iría contra el principio de libertad que tanto pregonaba el republicanismo), pues ya muchas provincias contaban con imprenta y sus propios periódicos.

\section{LA IMAGEN AMBIGUA DE LA REVOLUCIÓN}

Si bien los medios de transmisión de los acontecimientos revolucionarios constituyen un factor importante para medir el impacto en la sociedad peruana, conviene no olvidar que las revoluciones de 1789 y de 1848 generaron —como lo harían sus homólogas mexicana, rusa y china en su momento - un doble significado. Por un lado, proyectaron la imagen de ser un movimiento liberador, que permitía al pueblo retomar una soberanía usurpada y deshacerse de la opresión de un régimen venido a menos como el monárquico, para garantizar la igualdad y una adecuada redistribución de bienes. En el otro extremo, se hallaba una lectura menos triunfalista, aquella que estigmatizaba a las revoluciones como hechos violentos que socavaban las bases políticas y religiosas de la sociedad, además de provocar un sinfín de consecuencias negativas.

Ambas imágenes convivieron en desigual medida en el medio siglo que analizamos, y ello se debe al éxito o fracaso que tuvieron las autoridades no para restringir sino para orientar qué imagen era la que querían que se difundiese en el territorio bajo su control. De esta manera, el Perú empieza a formar parte de una escena internacional donde, a partir de la ejecución de Luis XVI y la declaratoria de guerra de los estados europeos a la Francia revolucionaria, las autoridades metropolitanas $y$, por ende, las coloniales deben llevar a cabo una serie de actividades contrarrevolucionarias.

La imagen negativa del evento revolucionario se articuló sobre la base de cuatro ejes principales: el regicidio, el ataque a la Iglesia y la religión católica, el terror y la guerra (Rosas Lauro, 2006: 99-156). El primer aspecto, el aguillotinamiento de Luis XVI, fue interpretado como un sacrilegio, debido al carácter sagrado del gobernante; un regicidio, por haberse perpetrado la ejecución del legítimo rey; y un parricidio, porque el monarca era considerado padre de la nación. El segundo tópico del discurso contrarrevolucionario, el ataque a la Iglesia y la religión católica, se presentó a través de la descripción de escenas impactantes de la persecución y ejecución de sacerdotes y monjas, la destrucción de los símbolos cristianos y la crítica de los principios católicos. La imagen que se proyectó era la de un proceso de carácter irreligioso y ateo. El tercer punto de la imagen negativa de la Revolución fue el terror, que se asoció a la actividad del Tribunal revolucionario, la figura simbólica de la guillotina y la omnipresencia de la muerte. El cuarto y último tópico, fue la guerra con sus consecuencias nefastas. Aparte de estos cuatro grandes temas, hay que considerar los principios subversivos del orden, en especial la libertad, que propugnaban los 
revolucionarios, identificados con el jacobinismo y el terrorismo, fantasmas muy presentes en el pensamiento político del siglo XIX.

Todo ello generó un miedo en las autoridades y la élite25, que mezcló temores ancestrales con otros coyunturales, lo cual debe ser tomado en consideración, pues hasta aquellos que podían simpatizar con la Revolución, lo hacían con una parte de su ideario mas no con la violencia y subversión del orden que había provocado. El caso de Juan Pablo Viscardo y Guzmán es un buen ejemplo. Estamos convencidos de que el discurso contrarrevolucionario característico de los escritos peruanos del siglo XIX está ya dado, en lo esencial, en la coyuntura de 1789. Luego se volverá a los mismos tópicos y argumentos, aspecto que queda evidenciado cuando se da el impacto de las revoluciones de 1848 y el debate entre conservadores y liberales.

Pero en el siglo XIX el término «revolución» ya tenía una carga de por sí negativa, y es que hacía referencia a los cambios bruscos y violentos que se operaban en la política postindependentista. De modo que la revolución del 48 ya encontraría un campo fértil para las discusiones sobre su posible impacto tanto en la capital como en las provincias (Leguía, 1989; Rosas Lauro, 2000b; Sobrevilla, 2002). Esta no podría haber encontrado mejor momento para llegar a nuestras costas: pues precisamente el tema que se debatía en nuestro medio estaba relacionado al de la soberanía popular. Para ser más precisos, habría que señalar que el tema clave era el de la ampliación del sufragio a las clases populares, tema poco agradable a conservadores, que pedían una serie de requisitos que en ese momento hacían imposible la participación de la mayoría de la población. Los liberales, en cambio, haciendo eco del 89, y anticipando su momento de gloria de 1855, defendían a capa y espada la inclusión de un mayor número de votantes. Fueron estos mismos liberales los que recibían con agrado noticias de Francia, especialmente las que incitaban a actuar: «No es posible permanecer quieto cuando todo el mundo se mueve. En Europa se desploman los tronos entre torrentes de sangre [...] iy nosotros dormimos?»26. O también aquellas que recordaban que el ejemplo para las jóvenes naciones hispanoamericanas se hallaba en Francia, en la medida en que la democracia era una «revolución permanente» 27.

La prensa contribuyó a incrementar la percepción negativa de la Revolución, e incidió en dos aspectos que preocupaban a los peruanos de ese entonces: el desorden y la crisis económica. Los conflictos entre los caudillos locales habían provocado serias alteraciones en la estabilidad social y económica del país, y la noticia de un evento del exterior que pudiese ahondar más la crisis, puesto que «cualquiera que sea la enseña de una revolución cualesquiera que sean los principios que ella proclame, ella no puede dejar de trastornar el orden social y de traer en pos de sí amargas y dolorosas consecuencias», como mencionaba un periódico cajamarquino28, o el efecto en la industria («Pasan de seis mil los establecimientos de comercio y fábricas que han quebrado desde la revolución de febrero»), de acuerdo con los redactores cuzqueños 29 .

Sin embargo, las autoridades no tenían que temer una «revolución» en el sentido estricto de la palabra en 1848, pues no se podía comparar la situación de «opresión» que justificaron los eventos parisinos con la situación peruana. Perú estaba entrando a una fase de estabilidad política con Castilla — merced a la consolidación de su posición de primus inter pares respecto a los demás caudillos regionales- junto con el auspicioso futuro económico que brindaría el guano. Amparados en una mal entendida libertad de imprenta, los periodistas de la prensa radical comenzaron a acusar al gobierno de irregularidades como sobornos e, intentando crear una atmósfera que propiciara un posible levantamiento popular, compararon a Castilla con su malogrado homólogo francés30.

\footnotetext{
${ }^{25}$ Sobre los temores de las autoridades y la élite entre el siglo XVIII y la Independencia, véase los trabajos de Scarlett O'Phelan, Arnaldo Mera, Cristina Mazzeo y José Ragas, en Rosas Lauro (2005).

26 El Comercio (Lima, 2853, martes 2 de enero de 1849).

27 El Demócrata Americano (Cuzco, Tomo I, número 76, 25 de mayo de 1847); El Zurriago (Lima, 16, 20 de mayo de 1848).

28 La Aurora (Cajamarca, 38, 17 de marzo de 1849).

29 Los Intereses del País (Lima, 7, 4 de setiembre de 1848).

30 El Zurriago (Lima, 18, 27 de mayo de 1848).
} 
A las medidas de control de los medios de comunicación y vigilancia de los espacios públicos, se sumaron otras que tenían como fin lograr la condena de la Revolución por parte de la población. De este modo, se organizaron las rogativas públicas y se desplegó una campaña de recaudación de donativos para financiar la guerra de España contra Francia. Esta se extendió no solo a la capital virreinal, sino a las demás provincias del Virreinato, siendo el caso de Arequipa uno de los mejor documentados, donde fue el Obispo quien lideró la campaña contrarrevolucionaria (Rosas Lauro, 2002). Este caso muestra como tanto las autoridades civiles como eclesiásticas participaron de estas acciones, de tal manera que el Estado virreinal, la Inquisición y la Iglesia tuvieron un papel importante. Estas mismas actividades se desarrollaron más sistemáticamente durante la coyuntura de 1808 (Nieto Vélez, 1960 a, b; Peralta, 2002). En ambos casos también se llegó a adoptar una serie de medidas militares para la defensa del reino por el temor a la llegada de navíos franceses. La dificultad para controlar el flujo de información en el periodo republicano hizo imposible que el Estado controlara a la opinión pública para una demostración de rechazo a lo ocurrido en Francia, considerando también que las relaciones entre Perú y Francia eran de una naturaleza distinta a las del siglo XVIII, donde los intereses de la Corona española estaban en juego.

\section{CONCLUSIÓN: LAS TRANSFORMACIONES DE LA CULTURA POLÍTICA}

Es evidente que las revoluciones no generaron un impacto inmediato en la sociedad peruana, ni desencadenaron un proceso similar al francés, bien sea porque los postulados que las respaldaban no sincronizaban con las necesidades locales o bien porque la férrea acción de las autoridades neutralizó una ya débil difusión. Después de todo, la política peruana no tendría por que haber reaccionado de manera ni similar ni automática a los eventos parisinos. Afirmar la correcta e inmediata sincronización entre Francia y Perú sería negar la dinámica propia del contexto andino y repetir lo señalado por la historiografía tradicional. El impacto de estas revoluciones se puede observar en otros aspectos, como la dinámica de los procesos informativos o la cultura política, que solo recientemente han llamado la atención del investigador31. En definitiva, existió una difusión de información sobre el evento revolucionario y un nivel de discusión entre un grupo reducido, primero, que luego con el ensanchamiento de la prensa en provincias, la rapidez de las noticias por el telégrafo y sectores urbanizados y más politizados, hizo imposible que las autoridades reaccionaran a tiempo. Sí consolidaron el periodismo y la difusión de información, ensanchando la opinión pública, bien a favor o en contra de ella. Los mecanismos de censura no resultaron del todo efectivos en un contexto absolutista — debilidad de la Inquisición, porosidad del control sobre los textos escritos, tolerancia de espacios públicos de discusión- o por la necesidad de mantener una aparente libertad de prensa en un escenario republicano, siendo el gobierno víctima de la trampa de los principios liberales que garantizaban la libre circulación de las ideas.

¿Cuál es el saldo que nos queda, suponiendo que fenómenos tan complejos como las revoluciones pudiesen ser reducidos a una ecuación? De todo lo expuesto, es posible señalar otras tres consecuencias directas de la Revolución en la cultura política peruana: la figura de Marianne y la simbólica, los banquetes y el socialismo. El primer caso remite inmediatamente al 89, mientras los dos últimos son herencia del 48.

La Revolución dotó de un lenguaje simbólico que permitió la legitimidad de los regímenes republicanos. No se trata de una herencia menor: en la necesidad por reemplazar la figura del monarca, los ideólogos franceses del 1789-1793 crearon un repertorio de prácticas y emblemas que fueron adoptados diligentemente por sus homólogos latinoamericanos, y que continuamos utilizando hasta el día de hoy en nombre del Estado-Nación. Aunque Marianne no tuvo una

31 Un balance historiográfico sobre la coyuntura de 1789 está en Claudia Rosas Lauro (2000c). 
amplia acogida, su silueta se deslizó entre las monedas (Dargent, 1989), los billetes, esculturas32, pinturas (Mujica, 2003) y publicaciones estableciéndose como la Madre Patria o la República. Más estudios sobre iconografía podrán dar cuenta de su difusión en otros niveles, pero no se puede soslayar que tuvo mucho más éxito que otros símbolos del 1789 como la guillotina o el árbol de la libertad. Incluso es necesario considerar las transformaciones en las ceremonias patrióticas y festividades cívicas (Lomné, 1991; Ortemberg, 2004; 2006).

La participación popular en los debates políticos fue una preocupación que los quarantehuitards parisinos y limeños asumieron con bastante diligencia. Pero no se trataba de la sola incorporación de personas al debate, sino de la logística en sí: cómo lograr que los oradores pudiesen hacer efectivo su mensaje a la mayor cantidad de personas. La solución que encontraron fue mediante la instalación de banquetes, que congregaban a multitudes en un ambiente de igualdad y participación política. En el Perú, estos banquetes —a los que se agregó el adjetivo de «reformistas»- funcionaron de manera efectiva en las campañas electorales y merecen estudiarse con mayor profundidad como se ha hecho, por ejemplo, para Chile.

También por esos mismos años, aparecieron las primeras referencias al socialismo, el cual sería nuestro tercer punto. La mención más temprana es de 1846, luego también aparecerá como parte del programa de un candidato peruano en 1850 en un periódico poco conocido, al que se agregaría la presunta existencia de un establecimiento «comunista» en 1852 . Hacia 1860 ya se hablaba cada vez más de los «rojos» y su presencia parece hacerse efectiva pocos años después de la celebración del primer centenario con la casi mítica «Comuna de Chalaco» en Piura. Pero el socialismo o comunismo, como se les llamaba indistintamente, era percibido como una variante extrema del liberalismo anticlerical, fuente de desorden y terror.

Para concluir, mencionemos que la imagen de la Revolución estuvo presente en las décadas siguientes, y en algunos casos se realizaban distinciones entre los dos procesos, dejando mal parada a la del 8933. Pero esta tendencia era propia de las sociedades occidentales, que reinterpretaban a la Revolución de acuerdo con los propósitos políticos de grupos determinados, multiplicando al infinito las imágenes que quedaban de ella, y superponiendo la de 48 a la del 30 y ésta a la del 89. En palabras de Eric Hobsbawm: «Todo el mundo tuvo su Revolución francesa» (Hobsbawm, 1992: 103). El recuerdo de la Revolución demostró a nivel mundial que podía adoptar diversas formas. Sin ir muy lejos, retomemos el caso de los masones que abría el presente texto: para ellos, era efectivamente motivo de alegría y celebración por cuanto confirmaba la duración misma de su organización; a pocas cuadras de su local, el 89 se vestía de luto y reunía la toma de la Bastilla con la guerra del Pacífico. Ambos eventos no tenían relación alguna, alejados temática y temporalmente uno del otro, pero el lenguaje con que se había impregnado al legado francés permitió que confluyera en un sentimiento colectivo de libertad (del enemigo chileno, de la tiranía), de igualdad (entre todos los que se hallaban reunidos, al margen de las jerarquías sociales) y de fraternidad (entre los peruanos y los franceses residentes en Lima) ese 14 de julio de 1889.

\footnotetext{
32 Se hicieron alegorías de la patria y la república en piedra de Huamanga durante el siglo XIX. Véase Wuffarden \& Majluf (1999).

33 El Zurriago (Lima, 15, 17 de mayo de 1848).
} 


\section{Referencias citadas}

\section{Fuentes primarias}

La Aurora. Cajamarca, 1848.

El Comercio. Lima, 1848-1849, 1889.

El Demócrata Americano. Cuzco, 1848.

Los Intereses del País. Lima, 1848.

El Zurriago. Lima, 1848.

«La Declaración de los Derechos del Hombre y del Ciudadano». París, 1789. Biblioteca Nacional de Lima, Manuscritos, c3728.

«Causa seguida contra Carlos Fornier por expresiones sediciosas». Archivo General de la Nación, Real Audiencia, Leg. 78, c. 950. Año 1794.

\section{Fuentes secundarias}

AGULHON, M., 1979 - Marianne au combat : I'imagerie et la symbolique républicaines de 1789 à 1880, 251 p.; París: Flammarion.

ALEGRE, M., 1997 - Poesía Mercurista: entre el conocimiento útil y el adorno del espíritu. Contracorriente, 1: 50-83; Lima.

CAHUATA, F., 1990 - Historia del periodismo cusqueño. Época republicana, 190 p.; Lima: SAGSA.

CAÑEQUE, A., 2004 - The King's Living Image. The Culture and Politics of Viceregal Power in colonial Mexico, 403 p.; Nueva York: Routledge.

CAPMANY, A., 1809 - Centinela contra franceses; Lima: Imprenta de Niños Expósitos. Procedente del Archivo del Museo Nacional de Arqueología, Antropología e Historia del Perú.

CARR, E. H., 1985 - La Revolución rusa: su lugar en la historia. In: 1917. Antes y después (La Revolución rusa): 27-59; Madrid: SARPE.

CHARTIER, R., 1995 - Espacio público, crítica y desacralización en el siglo XVIII, 263 p.; Barcelona: Gedisa.

CLÉMENT, J.-P., 1990 - La Révolution française dans le Mercurio Peruano. Caravelle, 54: $137-$ 151; Toulouse.

CLÉMENT, J.-P., 1997 - El Mercurio Peruano 1790-1795, 2 vols.; Frankfurt/Madrid: Vervuert/ Iberoamericana.

CUBAS, R., 2001 - Educación, elites e Independencia: el papel del Convictorio de San Carlos en la emancipación peruana. In: De los Borbones a Bolívar (O’Phelan, S., ed.): 289-317; Lima: Instituto Riva-Agüero.

DARGENT, E., 1989 - L'iconographie révolutionnaire dans I'Amérique espagnole. In: L'Image de la Révolution Française, vol. II: 1499-1508; París: Pergamon. Actas por el Bicentenario de la Revolución Francesa.

DARNTON, R., 1987 - La gran matanza de gatos y otros episodios en la historia de la cultura francesa, 367 p.; México: Fondo de Cultura Económica.

DE LA PUENTE CANDAMO, J. A., 1948 - Un documento sobre la influencia francesa en el Virreinato Peruano. Documenta, 1: 375-394; Lima.

DENEGRI LUNA, F., 1962-1963 - Apuntes para una bibliografía de periódicos cuzqueños (18221837). Revista Histórica, 26: 186-235; Lima.

DEUTSCHER, I., 1970 - Dos revoluciones. In: Herejes y renegados: 70-81; Barcelona: Ariel. 
DURAND, J. (ed.), 1983 [1793-1794] - Gazeta de Lima. De 1793 a Junio de 1794. Gil de Taboada y Lemos, 362 p.; Lima: COFIDE.

FONSECA, J., 2001 - Sin educación no hay sociedad: las escuelas lancasterianas y la educación primaria en los inicios de la República (1822-1826). In: De los Borbones a Bolívar (O'Phelan, S., ed.): 265-287; Lima: Instituto Riva-Agüero.

FORMENT, C., 2003 - Democracy in Latin America, 1760-1900. Vol. 1: Civic Selfhood and Public Life in Mexico and Peru, 454 p.; Chicago: University of Chicago Press.

FURET, F., 1999 - La Révolution en débat, 196 p.; París: Gallimard.

GAROFALO, L., 2005 - La sociabilidad plebeya en las pulperías y tabernas de Lima y el Cuzco, 1600-1690. In: Más allá de la dominación y la resistencia. Estudios de historia peruana, siglos XVI-XX (Drinot, P. \& Garófalo, L., eds.): 104-135; Lima: Instituto de Estudios Peruanos.

GAZMURI, C., 1992 - Formas de sociabilidad en Chile 1840-1940, 393 p.; Santiago de Chile: Fundación Mario Góngora.

GLAVE, L. M., 2004 - La república instalada. Formación nacional y prensa en el Cuzco 1825-1839, 251 р.; Lima: Instituto Francés de Estudios Andinos, Instituto de Estudios Peruanos.

GONZÁLEZ, C. A., 1999 - Los mundos del libro. Medios de difusión de la cultura occidental en las Indias de los siglos XVI y XVII, 260 p.; Sevilla: Universidad de Sevilla.

GONZÁLEZ, C. A., 2005 - Comercio colonial y cultura gráfica europea en el Perú del siglo XVIII. In: Ensayos de historia peruana (Millones, L., ed.): 37-72; Lima: Universidad Nacional Mayor de San Marcos.

GUERRA, F.-X., 1993 - Modernidad e independencias. Ensayos sobre las revoluciones hispánicas, 409 p.; México: Mapfre-Fondo de Cultura Económica.

GUERRA, F.-X., 2002 - «Voces del pueblo». Redes de comunicación y orígenes de la opinión en el mundo hispánico. Revista de Indias, 225: 317-384; Madrid.

GUERRA, F.-X., LEMPÉRIÈRE, A. \& BELLINGERI, M., 1998-Los espacios públicos en Iberoamérica. Ambigüedades y problemas. Siglos XVIII-XIX, 366 p.; México D.F.: Fondo de Cultura Económica-Centro Francés de Estudios Mexicanos e Iberoamericanos.

GUIBOVICH, P., 2003 - Censura, libros e Inquisición en el Perú colonial, 1570-1754, 429 p.; Sevilla: Universidad de Sevilla.

HAMPE, T., 1982 - La Revolución Francesa vista por el Mercurio Peruano: cambio político vs. reformismo criollo. Boletín del Instituto Riva-Agüero, 15: 163-178; Lima.

HOBSBAWM, E., 1992 - Los ecos de la Marsellesa, 174 p.; Barcelona: Crítica.

HOLGuíN, O., 1998 - El café de Bodegones y una sátira de El Comercio (Lima, 1857). In: Homenaje a don Aurelio Miró Quesada Sosa (López Martínez, H., ed.): 189-213; Lima: Academia Peruana de la Lengua, Academia Nacional de la Historia y Consorcio de Universidades.

LASTARRIA, J. V., 1967 - Lima en 1850. In: Viajeros en el Perú republicano (Tauro del Pino, A., ed.): 71-110; Lima: Universidad Nacional Mayor de San Marcos.

LEGUÍA, J. G., 1989 - Las ideas de 1848 en el Perú. In: Estudios Históricos: 107-136; Lima: Aloer.

LOMNÉ, G., 1991 - La Revolución Francesa y la simbólica de los ritos bolivarianos». Historia Crítica, 5: 3-17; Bogotá.

MACERA, P., 1977a - El periodismo en la Independencia. In: Trabajos de Historia IV: 325-342; Lima: Instituto Nacional de Cultura.

MACERA, P., 1977b - Bibliotecas peruanas del siglo XVIII. In: Trabajos de Historia I: 283-312; Lima: Instituto Nacional de Cultura.

MARTínEZ RIAZA, A., 1985 - La prensa doctrinal en la Independencia del Perú 1811-1824, 374 p.; Madrid: Instituto de Cooperación Iberoamericana.

MATEUS VENTURA, M. da G. (ed.), 2004 - Os espaços de sociabilidade na Ibero-América (sécs. XVI-XIX), 269 p.; Lisboa: Colibrí, Instituto de Cultura Ibero-Atlántica. 
MENDIBURU, M. de, 1879 - Apuntes históricos sobre la época de la dominación española. Cafés en Lima. Revista Peruana, 317: 125-127; Lima.

MORENO ALONSO, M., 1993 - La «Santa Trinidad» de la democracia en Lima en el jer Centenario de la Revolución Francesa. In: Masonería española (Ferrer Benimelli, J. A., ed.): II, 727-736; Zaragoza: Centro de Estudios Históricos de la Masonería Española. V Simposio Internacional de la Masonería española. Cáceres, 16-20 junio 1991.

MUJICA, R., 2003 - El Barroco Peruano, 2 vols.; Lima: Banco de Crédito del Perú.

NIETO VÉLEZ, A., 1960a - La política contra franceses y afrancesados en el Perú. Mercurio Peruano, 394: 68-85; Lima.

NIETO VÉLEZ, A., 1960b - La campaña literaria fidelista y antinapoleónica en el Perú. In: La Causa de la Emancipación del Perú: 339-354; Lima: Instituto Riva-Agüero.

ORTEMBERG, P., 2004 - Algunas reflexiones sobre el derrotero social de la simbología republicana en tres casos latinoamericanos. La construcción de las nuevas identidades políticas en el siglo XIX y la lucha por la legitimidad. Revista de Indias, 232: 697-720; Madrid.

ORTEMBERG, P., 2006 - Las primeras fiestas cívicas en el Perú independiente: emblemática y ceremonial bajo el Protectorado. Revista Andina, 43: 239-268; Cusco.

PERALTA, V., 1997 - La revolución silenciada. Hábitos de lectura y pedagogía política en el Perú, 1790-1814. Anuario de Estudios Americanos, 54(1): 107-134; Sevilla.

PERALTA, V., 2002 - En defensa de la autoridad. Política y cultura bajo el Gobierno del Virrey Abascal, Perú 1806-1816, 199 p.; Madrid: Consejo Superior de Investigaciones Científicas.

PERALTA, V., 2005 - Prensa y redes de comunicación en el Virreinato del Perú, 1790-1821. Tiempos de América, 12: 113-131; Madrid.

PÉREZ-MALLAÍNA, P.E., 1980 - Profesiones y oficios en la Lima de 1850. Anuario de Estudios Americanos, 37: 191-232; Sevilla.

RAGAS, J., 2003a - Cultura política y representación en el Perú republicano; Lima: Pontifica Universidad Católica del Perú. Tesis de Licenciatura.

RAGAS, J., 2003b - Los espejos rotos de la opinión pública: periodismo y política en el Perú (1845-1860). Debate y perspectivas, 3: 107-125; Madrid.

ROCHE, D., 1998 - France in the Enlightenment, 723 p.; Cambridge: Harvard University Press.

ROSAS LAURO, C., 1997 - La Imagen de la Revolución Francesa en el Virreinato Peruano a fines del siglo XVIII; Lima: Pontificia Universidad Católica del Perú. Tesis de Licenciatura.

ROSAS LAURO, C., 2000a - El imaginario político regional en los periódicos cuzqueños entre la Independencia y la República. In: De los Borbones a Bolívar. La Independencia en el Perú (O'Phelan, S., ed.): 99-118; Lima: Instituto Riva-Agüero.

ROSAS LAURO, C., 2000b - Los ecos del 48 en el Cuzco. Yachaywasi, 7: 51-57; Lima.

ROSAS LAURO, C., 2000c - Loas y diatribas. La historiografía peruana frente a la Revolución Francesa. In: Félix Denegri Luna. Homenaje: 691-708; Lima: PUCP.

ROSAS LAURO, C., 2002 - Por el Trono y el Altar. El Obispo Chávez de la Rosa y su campaña contra la Revolución Francesa en Arequipa. In: Sobre el Perú. Homenaje a José Agustín de la Puente Candamo (Guerra, M. \& Holguín, O., eds.): II, 1107-1139; Lima: Pontificia Universidad Católica del Perú.

ROSAS LAURO, C., ed., 2005 - El miedo en el Perú (siglos XVI-XX), 285 p.; Lima: Seminario Interdisciplinario de Estudios Andinos, Pontificia Universidad Católica del Perú.

ROSAS LAURO, C., 2007 - Del Trono a la Guillotina. El impacto de la Revolución Francesa en el Perú (1789-1808), 287 p.; Lima: Pontificia Universidad Católica del Perú, Instituto Francés de Estudios Andinos, Embajada de Francia.

ROSAS MOSCOSO, F., 1989 - La Revolución Francesa en la prensa colonial: la Gaceta de Lima. Revista Internacional de Periodismo Mensaje, 20: 42-48; Lima. 
ROSSI Y RUBÍ, J., 1965 [1971] - «Rasgo histórico y filosófico sobre los Cafés de Lima», Mercurio Peruano, t. I, n 12, 10 de febrero de 1791; Lima: Biblioteca Nacional del Perú. Edición facsimilar.

SCHAMA, S., 1990 - Ciudadanos: crónica de la Revolución Francesa, 905 p.; Buenos Aires: Javier Vergara.

SOBREVILLA, N., 2002 - The Influence of the European 1848 Revolutions in Peru. In: The European Revolutions of 1848 and the Americas (Thomson, G., ed.): 191-216; London: Institute of Latin American Studies.

WALKER, Ch., 2000 - La orgía periodística: prensa y cultura política en el Cuzco durante la joven república. In: Homenaje a Félix Denegri Luna: 749-767; Lima: Pontificia Universidad Católica del Perú.

WUFFARDEN, L.E. \& MAJLUF, N., 1999 - La piedra de Huamanga: lo sagrado y lo profano, 170 p.; Lima: Museo de Arte de Lima. 